\title{
Cooperative Learning: A Systematic Review of the Economy Subject in the Curriculum of Secondary Education
}

\author{
Mercedes MORERA-FERNANDEZ ${ }^{1}$, Aram MORERA-MESA ${ }^{2}$, Armando L. MORERA- \\ FUMERO $^{3}$
}

\begin{tabular}{l} 
ARTICLE INFO \\
\hline Article History: \\
Received 15.04.2019 \\
Received in revised form \\
17.12 .2019 \\
Accepted \\
Available online 01.01 .2020
\end{tabular}

\begin{abstract}
Cooperative learning (CL) has been applied to different subjects in different educational levels. Economy as a subject has been introduced recently in the curriculum of secondary schools compared to other classical subjects such as mathematics or literature. The aim of this research is to systematically review the application of CL in the teaching of economy in secondary education. Methods: a search in the Web of Science (WOS), Scopus and EBSCOhost (Academic Search Complete, Business Source Ultimate, EconLit with full text, ERIC, Library, information science \& technology abstract, PsycArticles, PsycInfo) was carried out from database inception to December 1st, 2019. The query for the search was as follows: "secondary school or secondary education" AND "cooperative learning or collaborative learning" AND "economy or finances or business". As secondary sources of bibliography, we used the reference list from the selected articles. Results: A total of 428 documents were retrieved from the databases searches. One paper was retrieved from the secondary sources. EBSCOhost was the database that elicited most documents, 325 against the 29 documents that were retrieved from Scopus and the 74 documents retrieved from WOS. A total of 48 duplicates were elicited from the three databases. After removing the duplicates 380 document were scrutinized to look for eligibility. No single paper met the criteria except for the paper found through the secondary sources. Conclusion: Despite of the importance of the subject of economy in the curriculum of secondary education, only one empirical paper was found in our review. Future research on this topic should try to fill this gap.
\end{abstract}

(C) IJERE. All rights reserved

Keywords:

Collaborative learning, cooperative learning, secondary education, economy.

\section{INTRODUCTION}

The term cooperative learning (CL) refers to the teaching and learning processes that have been created under the paradigm of cooperation. In cooperative situations the goal attainments of participants are positively correlated; individuals perceive that they can reach their goals if and only if the other group members do. Thus, the subjects seek an outcome that is beneficial for each subject and beneficial to all other subjects with whom the subject is cooperatively linked (Deutsch, 1949). CL has been defined as the instructional use of small groups so that students work together to maximize their own and each other's learning (Johnson, Johnson, \& Holubec, 2013). Several instruments have been developed to study CL (Fernandez-Rio, Cecchini, Méndez-Giménez, Méndez-Alonso, \& Prieto, 2017; Kiper, 2016).

In general, $\mathrm{CL}$ is placed in contrast to competitive learning in which the subjects work against each other to achieve the goal that only one or few can obtain. In competitive situations, the goals of each subject are so linked that there is a negative correlation among their goal attainments; each subject perceives that he/she can reach his/her goal if and only if the other cannot reach their goals (Deutsch, 1949).

CL techniques have been used in the different levels of learning and teaching, from primary (Genç, 2016) and secondary education (Gambari \& Yusuf, 2014) to university (Hakim, \& Sakti, 2019) as well as to different topics, such as mathematics (Pons, Prieto, Lomeli, Bermejo, \& Bulut, 2014), economy (Rokhmah \& Subroto, 2019), science (Topping et al., 2011), music (Hwong, Caswell, Johnson, \& Johnson, 1993), business communication (Janah \& Subroto, 2019) and many other topics.

In Spain, the subject of economy has been introduced as a subject in education (LEY ORGANICA 1/1990. Ordenación General del Sistema Educativo, 1990) recently in contrast to more traditional subjects such as literature or mathematics that were introduced many years ago (LEY DE 26 DE FEBRERO DE 1953. Ordenación de la Enseñanza Media, 1953).

1Master in Education. Degree in Business Administration and Management. University of La Laguna. Corresponding e-mail: mercedes.morera.2018@gmail.com; orcid.org/0000-0002-7671-294X 
Due to the lack of empirical data on this topic, our aim is to systematically review the literature on the application of CL strategies in teaching the economy subject in secondary education.

\section{METHODS}

Papers were identified by searching the following electronic databases: Web of Science (WOS), Scopus and EBSCOhost (Academic Search Complete, Business Source Ultimate, EconLit with full text, ERIC, Library, information science \& technology abstract, PsycArticles, PsycInfo). The period of the search ranged from database inception to December 1st, 2019. No limits were applied for language. As secondary sources of bibliography, we used the reference list from the selected articles.

The query for the search was as follows: "secondary school or secondary education" AND "cooperative learning or collaborative learning" AND "economy or finances or business". Appendix 1 includes the specific search query for the electronic databases as well as the results for each database. Manuscripts were organised using the Mendeley reference manager. The number of references obtained from each search query for each database was recorded and a running total constructed.

After accounting for duplicates, the titles and abstracts of all returned records were reviewed by two independent authors (MMF and AMM) to identify potentially relevant studies. Finally, the full text of all potentially relevant studies was reviewed (MMF and AMM) to determine the final study selection. Where the eligibility and relevance of papers was not clear, a third author (ALMF) was available to meet and discuss with the other authors.

Studies were included if they investigated the application of CL in the teaching of the subject of economy in secondary education. Only primary research of original data and analytic designs were included.

\section{RESULTS}

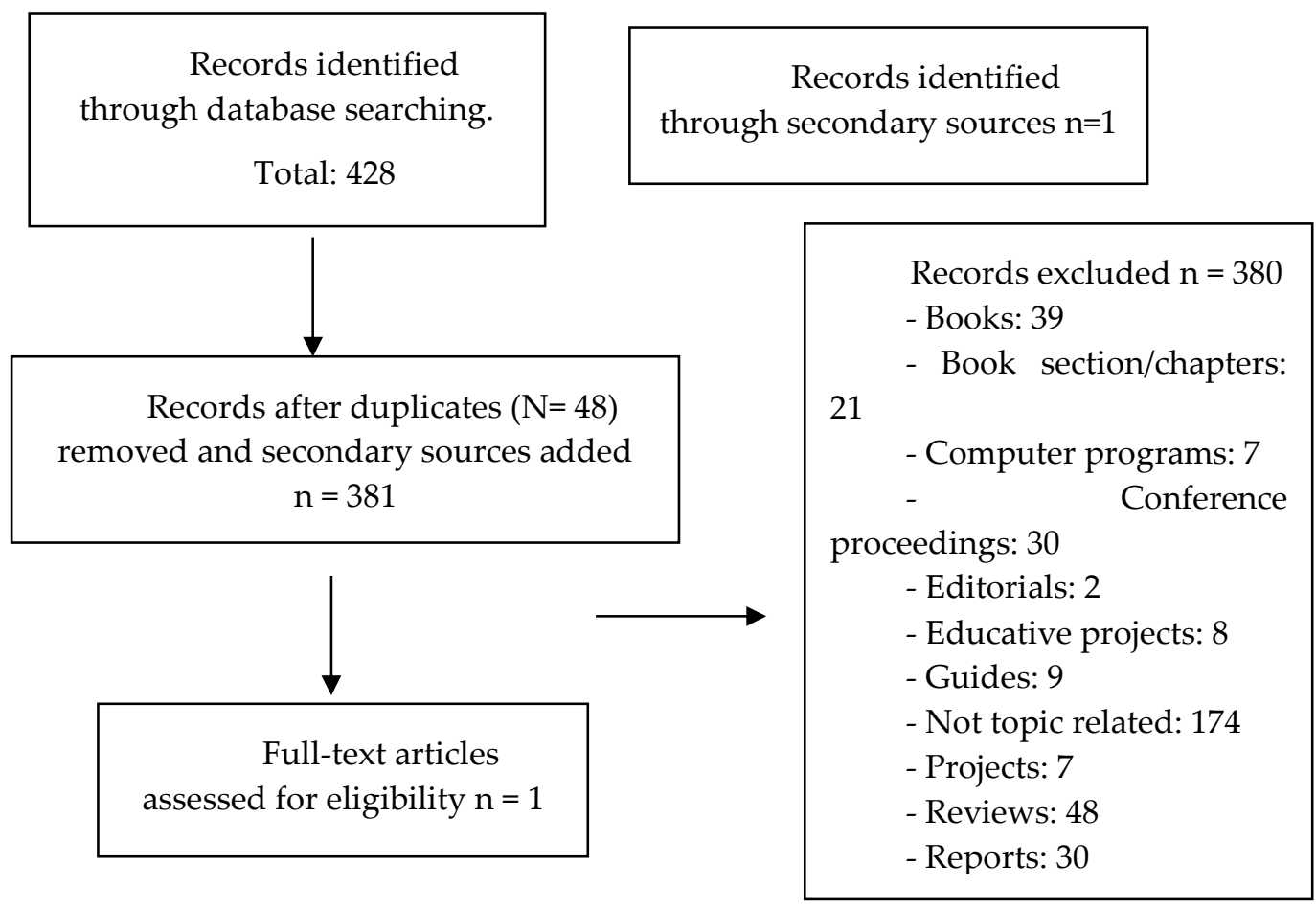

Figure 1: Flow chart of document identification and selection for the review.

A total of 428 documents were retrieved from the database search and one document was identified through secondary sources. EBSCOhost was the database that elicited most documents, 325 against the 29 
documents that were retrieved from Scopus and the 74 documents retrieved from WOS. The specific results for each step of the search by databases are presented in the appendix 1.

A total of 48 duplicates were elicited from the three databases. After removing the duplicates 380 document were scrutinized to look for the eligibility. No single paper met the criteria. The most important group of papers that were not eligible was comprised by documents not related with the topic of study, 174 documents. The second most important group of documents rejected was comprised by 60 book and book section/chapters. Review documents was the third group that contained 48 papers. Conference proceedings and reports contained 30 documents each one. Only one paper, obtained from secondary sources, related to our review was elicited (Rokhmah \& Subroto, 2019). Agreement on final study selection was $100 \%$ between the two reviewers.

\section{DISCUSION}

The most notable result from our review on Cooperative Learning in the subject of economy in secondary education is the near absence of empirical studies. Only one paper was identified (Rokhmah \& Subroto, 2019) through the reference list of another (Rohmat et al., 2019).

In a recent paper (Johnson \& Johnson, 2014), the authors point to the four challenges that the 21st century will bring (global interdependence, increasing number of democracies, creative entrepreneurs and the growing importance of interpersonal relationships) and how cooperation plays a central role and how the tools offered by the cooperative learning will help meeting these challenges.

Few research papers have been published on CL in economy but those researches have been carried out in senior high school students (Rohmat et al., 2019) where the application of a CL tool, jigsaw type, improved the learning outcomes. In a recent paper where the researchers applied the jigsaw type of CL to students of cycle I and cycle II of accounting, they found that the jigsaw did not succeed in the student of cycle I, but the jigsaw type of CL succeeded in students of cycle II (Rokhmah \& Subroto, 2019)

It can be concluded that despite of the importance of the subject of economy in the curriculum of secondary education, only one empirical paper was found in our review. Future research on this topic should try to fill this gap.

\section{REFERENCES}

Deutsch, M. (1949). A theory of co-operation and competition. Human Relations, 2(2), 129-152. https://doi.org/10.1177/001872674900200204

Fernandez-Rio, J., Cecchini, J. A., Méndez-Giménez, A., Méndez-Alonso, D., \& Prieto, J. A. (2017). Diseño y validación de un cuestionario de medición del aprendizaje cooperativo en contextos educativos. Anales de Psicologia, 33(3), 680-688. https://doi.org/10.6018/analesps.33.3.251321

Gambari, I. A., \& Yusuf, M. O. (2014). Effects of three cooperative learning strategies on the performance of secondary school students in physics. Chemistry, 23(3), 353-373.

Genç, M. (2016). An evaluation of the cooperative learning process by sixth-grade students. Research in Education, 95(1), 19-32. https://doi.org/10.7227/RIE.0018

Hwong, N. C., Caswell, A., Johnson, D. W., \& Johnson, R. T. (1993). Effects of cooperative and individualistic learning on prospective elementary teachers' music achievement and attitudes. Journal of Social Psychology, 133(1), 53-64. https://doi.org/10.1080/00224545.1993.9712118

Janah, I. I. N., \& Subroto, W. T. (2019). Comparison Of Cooperative Learning Models With Inquiry on Student Learning Outcomes. International Journal of Educational Research Review, 4(2), 178-182. https://doi.org/10.24331/ijere.517995

Johnson, D.W., Johnson, R. T., \& Holubec, E. J. (2013). Cooperation in the classroom Title (9th ed.). Interaction Book Company.

Johnson, David W., \& Johnson, R. T. (2014). Aprendizaje cooperativo en el siglo XXI. Anales de Psicologia, 
30(3), 841-851. https://doi.org/10.6018/analesps.30.3.201241

Kiper, A. (2016). Cooperative learning scale: Validity and reliability. International Journal of Educational Research, 1(2), 42-48. https://doi.org/10.1016/j.ijer.2008.07.005

LEY DE 26 DE FEBRERO DE 1953. Ordenación de la Enseñanza Media (pp. 1119-1130). (1953).

LEY ORGANICA 1/1990. Ordenación General del Sistema Educativo (pp. 28927-28942). (1990).

Pons, R. M., Prieto, M. D., Lomeli, C., Bermejo, M. R., \& Bulut, S. (2014). Cooperative learning in mathematics: A study on the effects of the parameter of equality on academic performance. Anales de Psicologia, 30(3), 832-840. https://doi.org/10.6018/analesps.30.3.201231

Rohmat, N. F., Hakim, L., \& Sakti, N. C. (2019). Implementation of jigsaw type cooperative learning model to improve economics learning results. International Journal of Educational Research Review, 4(3), 350-357. https://doi.org/10.24331/ijere.573871

Rokhmah, N. F., \& Subroto, W. T. (2019). Application of cooperative learning jigsaw type to improve learning outcomes of economic introduction and business. International Journal of Educational Research Review, 4(2), 238-244. https://doi.org/10.24331/ijere.518067

Topping, K. J., Thurston, A., Tolmie, A., Christie, D., Murray, P., \& Karagiannidoud, E. (2011). Cooperative learning in science: Intervention in the secondary school. Research in Science and Technological Education, 29(1), 91-106. https://doi.org/10.1080/02635143.2010.539972

\section{APPENDIX 1}

Search strategy. Last updated: December 1st, 2019

1. (economy OR finances OR business)

Web of science: $1221580 \quad$ Scopus: $1965126 \quad$ EBSCOhost: 9209872

2. (secondary school OR secondary education)

Web of science: $99589 \quad$ Scopus: $70845 \quad$ EBSCOhost: 640333

3. ((cooperative AND learning) OR (collaborative AND learning))

Web of science: 62493

Scopus: 20316

EBSCOhost: 46305

4. 1 AND 2

Web of science: 3147

Scopus: 4067

EBSCOhost: 65885

5. 3 AND 4

Web of science: 74

Scopus: 29

EBSCOhost: 325 